\title{
Results from the Scottish National HAI Prevalence Survey
}

\author{
J. Reilly ${ }^{a, *}$, S. Stewart ${ }^{a}$, G.A. Allardice ${ }^{b}$, A. Noone ${ }^{a}$,

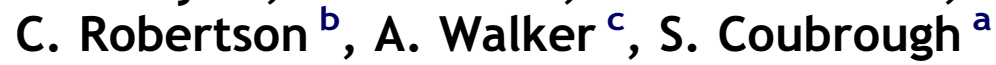 \\ ${ }^{a}$ Health Protection Scotland, Glasgow, UK \\ ${ }^{\mathrm{b}}$ Robertson Centre for Biostatics, University of Glasgow, UK \\ c Glasgow University, Glasgow, UK
}

\author{
KEYWORDS \\ Prevalence; Survey; \\ Healthcare-associated \\ infection; Nosocomial \\ infection
}

\begin{abstract}
Summary A national point prevalence survey was undertaken over the period of one calendar year in Scotland from October 2005 to October 2006. The prevalence of healthcare-associated infection (HAI) was $9.5 \%$ in acute hospitals and $7.3 \%$ in non-acute hospitals. The highest prevalence of $\mathrm{HAl}$ in acute hospital inpatients was found in the following specialties: care of the elderly $(11.9 \%)$, surgery $(11.2 \%)$, medicine $(9.6 \%)$ and orthopaedics $(9.2 \%)$. The lowest prevalence was found in obstetrics $(0.9 \%)$. The most common types of $\mathrm{HAl}$ in acute hospital inpatients were: urinary tract infections $(17.9 \%$ of all $\mathrm{HAl})$, surgical site infections $(15.9 \%)$ and gastrointestinal infections (15.4\%). In non-acute hospitals one in ten inpatients in two specialties (combined) medicine $(11.4 \%)$ and care of the elderly (7.8\%) was found to have HAI, and one in 20 inpatients in psychiatry $(5.0 \%)$ had HAl. In non-acute hospital patients, urinary tract infections were frequent $(28.1 \%$ of all HAl) and similarly skin and soft tissue infection ( $26.8 \%$ of all HAl). When combined, these two HAl types affected $4 \%$ of all the inpatients in non-acute hospitals. This is the first survey of its kind in Scotland and describes the burden of $\mathrm{HAl}$ at a national level.
\end{abstract}

\section{Introduction}

\footnotetext{
* Corresponding author. Address: Health Protection Scotland, Clifton House, Clifton Place, Glasgow G3 7LN, UK. Tel.: +44 0141300 1100; fax: +4401413001170.

E-mail address: jacqui.reilly@hps.scot.nhs.uk
}

Healthcare-associated infections (HAls) are infections not present at the time the patient's healthcare begins, but which arise afterwards. There is evidence from several countries that HAls are 
avoidable and costly to the health service and to patients. ${ }^{13}$ HAls are also a source of discomfort, disability and distress to the individuals affected and can be fatal in some circumstances.

In Scotland, the Ministerial HAl Task Force (HAITF), led by the Chief Nursing Officer (CNO), is developing measures to reduce the burden of HAl. It requires robust, representative baseline data and trend information on the burden and cost of $\mathrm{HAl}$ in Scotland in order to assess the impact of the measures that are being put in place to reduce HAI and to assist in the development of future policy.

A rolling point prevalence HAl survey, in which a ward in each hospital is surveyed in one day, was selected as a feasible proposition and of acceptable cost if all HAl types in all acute hospitals and a sample of non-acute hospitals in Scotland were to be monitored.

The aims of the survey were:

To provide the HAITF with baseline information on the total prevalence of HAl in Scottish hospitals and its burden in terms of health service utilisation and costs. This information would be available to guide priority setting in the development of strategy and policy.

To develop a consistent methodology for prevalence surveys which, when repeated at intervals, would allow the impact of measures taken nationally to reduce the burden of HAI to be evaluated through an analysis of trends.

\section{Methods}

For the purposes of this survey, HAl was defined as infection arising $\geq 48 \mathrm{~h}$ after admission to hospital and which was considered not present or incubating on admission. A prevalent HAl was considered present when the patient had signs and symptoms that met one of the Centers for Disease Control and Prevention (CDC) definitions, or had one or more signs or symptoms included in one of the CDC definitions and was being treated for the infection (with therapy). CDC's HAl case definitions were adopted as these are widely used internationally. ${ }^{4}$ These definitions comprehensively categorise HAI according to the organ/tissue system affected.

Data collection was undertaken on weekdays. All ward and patient data were entered onto a specially designed database held on a small portable 'tablet' personal computer (PC) while the data collectors were on the ward. All data collection on a ward was completed within one day.

Data collectors followed a standard procedure in their surveillance of a ward. Local nominated link members of the HAl control team introduced the data collectors onto the wards. Prior to commencing the inpatient data collection, data on ward characteristics on the day of data collection (ward type, bed numbers, staff numbers and types) were collected with assistance from the nurse in charge.

The data collectors sought information on eligible inpatients from all relevant sources including case records, all results of special examinations including microbiology reports, X-ray reports, temperature charts, prescribing records, nursing notes and, where necessary, through discussion with clinical staff and by direct clinical observation. The design of the survey required the data collector to make an initial decision based on this information as to whether the inpatients showed signs of a specific HAl, criteria for which were included and accessible on the PC. They were required to check every sign and symptom included in the relevant CDC HAl definition which was met by a patient they had decided had HAl. The decision as to the presence or absence of HAl was that of the data collector. They were able to seek further help from epidemiology consultants at HPS if they had any remaining doubts about the diagnosis of $\mathrm{HAl}$ according to the CDC definition.

Data were exported from each data collector's tablet PC on a weekly basis. The export procedure produced Microsoft Excel files. These were subsequently imported into a Microsoft Access database. Within the Microsoft Access database, algorithms were used to examine data consistency and validity. Algorithms were used to confirm that the criteria recorded met CDC HAl case definitions and with therapy definitions. Data quality and the performance of the data collection tool were monitored throughout the survey.

Inter-rater reliability (IRR) validation exercises were undertaken on two occasions during the survey to measure the consistency of data collection between data collectors. A crossover study design was adopted, requiring a sample of patients to be surveyed by the whole data collection team over the course of a single day. While the overall level of IRR was reassuringly high for the selected data items, these exercises revealed limitations to the assessment methodology in a dynamic healthcare setting. The validation recorded a $100 \%$ agreement for diagnosis of HAl type.

\section{Results}

In total, 13754 inpatients were included in the Scottish National Prevalence Survey: 11608 in all 
45 acute hospitals and 2146 in a sample of 22 nonacute hospitals in Scotland. Bed occupancy was calculated to be $\sim 80 \%$, which is consistent with the level of $8182 \%$ reported by the Information and Services Division over the last six years. ${ }^{5}$ Age and gender distributions are given in Figures 1 and 2 .

In acute hospitals, 1103 of the total of 11608 inpatients were found to have $\mathrm{HAl}$, giving an unadjusted overall prevalence of inpatients with $\mathrm{HAl}$ in acute hospitals of $9.5 \%(95 \% \mathrm{Cl}: 8.8$ 10.2). Of the 1103 inpatients with HAl, $126(11.4 \%)$ had more than one infection. A total of 1243 HAls which met the survey HAl case definition were found to be present, 831 (66.9\%) fully meeting the CDC criteria and 966 (77.7\%) meeting the criteria of 'one or more symptoms included in the survey definition and on antimicrobial therapy for HAl' ('with therapy'). Of the acute hospital cases, $44.6 \%$ met both HAl definitions.

In the non-acute hospital sample, 157 of 2146 inpatients were found to have HAl, giving a crude overall prevalence of inpatients with HAl of $7.3 \%$ $(95 \% \mathrm{Cl}: 6.0$ 8.6). Seven of the 157 inpatients with $\mathrm{HAl}$ had more than one infection. Of the 164 HAls diagnosed, 97 (59.1\%) fully met the CDC incidence definitions and $144(87.8 \%)$ met the 'with therapy' definition. Forty-seven percent of cases in nonacute hospitals met both infection definitions.
Among acute hospital inpatients, these data illustrate that all the CDC HAl categories contribute to the total burden of HAI (Table I). The main infection types in rank order were: urinary tract infection $(N=222)$; surgical site infection $(N=$ 197); gastrointestinal infection $(N=191)$; eye, ear, nose, throat and mouth infections $(N=155)$; lower respiratory tract infections other than pneumonia $(N=139)$; skin and soft tissue infections $(N=137)$; pneumonia $(N=109)$. CDC combines eye, ear, nose, throat and mouth infections as a single major category of infection. They are grouped by anatomical location but in clinical practice the specialties are quite distinct. When the narrower infections are disaggregated the most common infection type is of the oral cavity (with 107 infections) and the other 48 are divided throughout the infection types. For this reason eye, ear, nose, throat and mouth infections will not be discussed as a single group.

The highest prevalence of HAl in acute hospital inpatients was found in the following specialties: care of the elderly (11.9\%; 95\% Cl: $10.013 .7 \%)$, surgery (11.2\%; $95 \% \mathrm{Cl}$ : $9.512 .9 \%)$, medicine (9.6\%; $95 \% \mathrm{Cl}: 8.510 .7 \%)$ and orthopaedics (9.2\%; 95\% Cl: 7.3 11.1) (Table II). Obstetrics had a low HAI prevalence $(0.9 \%)$.

The specialty distribution of non-acute hospital inpatients differs from that of acute hospital

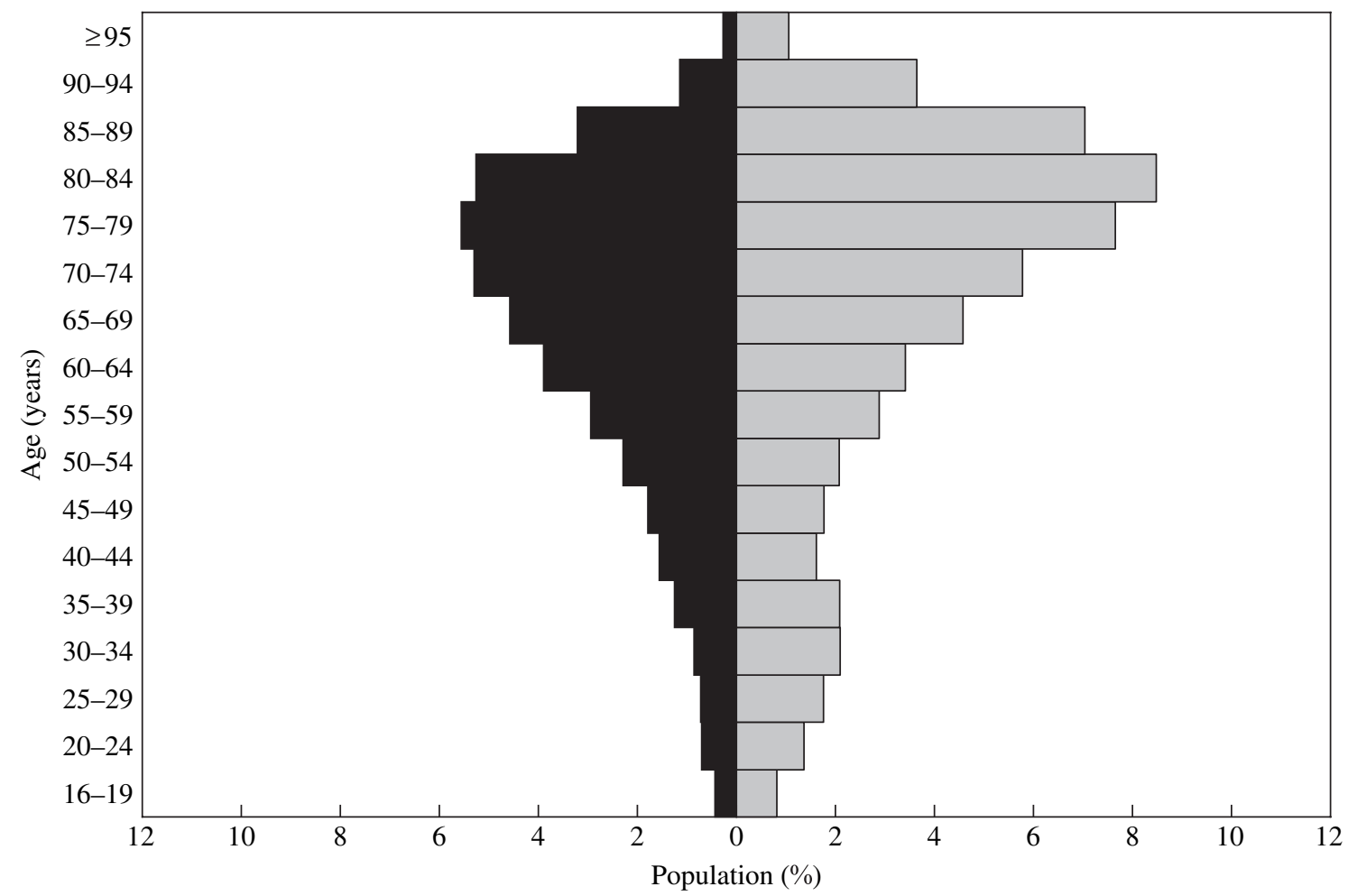

Figure 1 Acute hospitals: inpatients surveyed by age group and sex $(N=11608)$. Black bars, males; grey bars, females. 


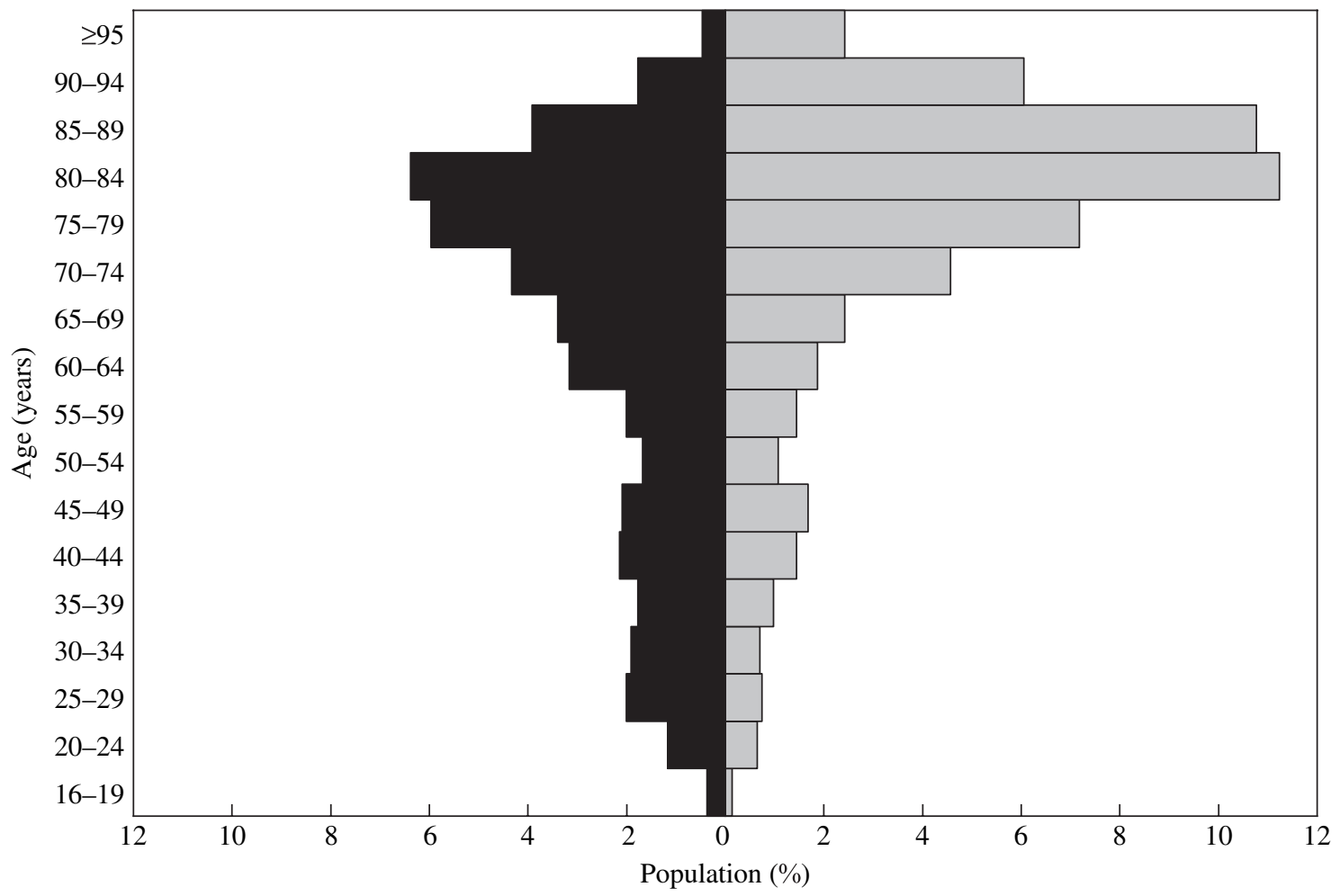

Figure 2 Non-acute hospitals: inpatients surveyed by age group and sex $(N=2146)$. Black bars, males; grey bars, females.

inpatients and therefore the pattern of HAl contributing to the burden of HAl is different (Table III): urinary tract infection $(N=46)$, skin and soft tissue infection $(N=44)$, eye, ear, nose, throat or mouth infection $(N=22)$, gastrointestinal infection $(N=20)$ and lower respiratory tract infection other

Table I Acute hospitals: number and percentage of healthcare-associated infection (HAl) cases by $\mathrm{HAl}$ type

\begin{tabular}{lrr}
\hline HAl type & \multicolumn{2}{c}{ Infections } \\
\cline { 2 - 3 } & No. & $\%$ \\
\hline Bone and joint & 6 & 0.5 \\
Blood stream & 55 & 4.4 \\
Central nervous system & 2 & 0.2 \\
Cardiovascular system & 11 & 0.9 \\
Eye, ear, nose, throat or mouth & 155 & 12.5 \\
Gastrointestinal & 191 & 15.4 \\
Lower respiratory tract infection & 139 & 11.2 \\
other than pneumonia & & \\
Pneumonia & 109 & 8.8 \\
Reproductive & 17 & 1.4 \\
Systemic & 2 & 0.2 \\
Surgical site & 197 & 15.9 \\
Skin and soft tissue & 137 & 11.0 \\
Urinary tract & 222 & 17.9 \\
Total & 1243 & 100.0 \\
\hline
\end{tabular}

than pneumonia $(N=19)$ made up $92 \%$ of infections. The only categories of HAl that were not found in non-acute hospital inpatients were bloodstream infections, central nervous system

Table II Acute hospitals: prevalence of healthcareassociated infection (HAl) in eligible inpatients by specialty

\begin{tabular}{|c|c|c|c|c|}
\hline \multirow[t]{2}{*}{ Specialty } & \multirow{2}{*}{$\begin{array}{c}\text { Inpatients } \\
\text { with HAI } \\
\text { N }\end{array}$} & \multirow{2}{*}{$\begin{array}{c}\text { HAl } \\
\text { prevalence } \\
\text { within } \\
\text { specialty } \\
\% \\
\end{array}$} & \multicolumn{2}{|c|}{$95 \% \mathrm{Cl}$} \\
\hline & & & Lower & Upper \\
\hline $\begin{array}{l}\text { Care of the } \\
\text { elderly }\end{array}$ & 199 & 11.9 & 10.0 & 13.7 \\
\hline Dentistry & 2 & 12.5 & 4.1 & 20.9 \\
\hline Gynaecology & 10 & 4.8 & 1.2 & 8.4 \\
\hline Haematology & 8 & 6.7 & 2.0 & 11.3 \\
\hline Medicine & 491 & 9.6 & 8.5 & 10.7 \\
\hline Obstetrics & 4 & 0.9 & 0.0 & 1.9 \\
\hline Oncology & 12 & 8.8 & 2.0 & 15.7 \\
\hline Orthopaedics & 105 & 9.2 & 7.3 & 11.1 \\
\hline Other & 0 & 0.0 & - & - \\
\hline Psychiatry & 9 & 3.5 & 0.3 & 6.7 \\
\hline Surgery & 247 & 11.2 & 9.5 & 12.9 \\
\hline Urology & 16 & 6.3 & 3.0 & 9.5 \\
\hline Total & 1103 & 9.5 & 8.8 & 10.2 \\
\hline
\end{tabular}


Table III Non-acute hospital: number and percentage of healthcare-associated infection (HAl) cases by HAl type

\begin{tabular}{lrr}
\hline HAl type & \multicolumn{2}{c}{ Infections } \\
\cline { 2 - 3 } & No. & \multicolumn{1}{c}{$\%$} \\
\hline Bone and joint & 1 & 0.6 \\
Cardiovascular system & 1 & 0.6 \\
Eye, ear, nose, throat or mouth & 22 & 13.4 \\
Gastrointestinal & 20 & 12.2 \\
Lower respiratory tract & 19 & 11.6 \\
infection other than pneumonia & & \\
Pneumonia & 4 & 2.4 \\
Reproductive system & 2 & 1.2 \\
Surgical site & 5 & 3.1 \\
Skin and soft tissue infection & 44 & 26.8 \\
Urinary tract infection & 46 & 28.1 \\
Total & 164 & 100.0 \\
\hline
\end{tabular}

infections and systemic infections. Although some more severe HAls, which particularly affect acute hospital inpatients, e.g. pneumonias and surgical site infections, are very much less common, they do occur in non-acute hospitals.

If all respiratory tract infections are combined (lower respiratory tract infection and pneumonia) then this group makes up a large proportion of the total HAl. These two infection types are defined separately according to CDC grouping.

Overall in non-acute hospitals, one in ten inpatients in the medical specialties of medicine and care of the elderly (combined) were found to have $\mathrm{HAl}$ and one in 20 inpatients in the specialty psychiatry had HAI (Table IV); these comprised principally skin and soft tissue and urinary tract

Table IV Non-acute hospitals: prevalence of healthcare-associated infection (HAl) in eligible inpatients by specialty

\begin{tabular}{|c|c|c|c|c|}
\hline \multirow[t]{2}{*}{ Specialty } & \multirow{2}{*}{$\begin{array}{c}\text { Inpatients } \\
\text { with HAI } \\
\text { No. }\end{array}$} & \multirow{2}{*}{$\begin{array}{c}\text { HAl } \\
\text { prevalence } \\
\text { within } \\
\text { specialty } \\
\%\end{array}$} & \multicolumn{2}{|c|}{$95 \% \mathrm{Cl}$} \\
\hline & & & Lower & Upper \\
\hline $\begin{array}{l}\text { Care of } \\
\text { the elderly }\end{array}$ & 34 & 7.8 & 4.7 & 10.9 \\
\hline Medicine & 64 & 11.4 & 8.6 & 14.1 \\
\hline Orthopaedics & 1 & 7.1 & - & - \\
\hline Psychiatry & 56 & 5.0 & 3.5 & 6.4 \\
\hline Surgery & 2 & 40.0 & - & - \\
\hline Urology & 0 & 0.0 & - & - \\
\hline Total & 157 & 7.3 & 6.0 & 8.6 \\
\hline
\end{tabular}

infections. The distribution of the HAl across the categories for the inpatients with HAl in all specialties is given in Table IV. The highest prevalence of $\mathrm{HAl}$ in non-acute hospital inpatients was found in the following specialties: medicine $(11.4 \%$; $95 \%$ $\mathrm{Cl}: 8.614 .1 \%)$, care of the elderly $(7.8 \% ; 95 \% \mathrm{Cl}$ : 4.7 10.9\%), orthopaedics (7.1\%) and psychiatry $(5.0 \%$; $95 \% \mathrm{Cl}: 3.56 .4 \%)$. The numbers of patients in surgery and orthopaedics are small and therefore should be interpreted with caution.

\section{Discussion}

This was the first prevalence survey of HAI in Scotland, which included acute and non-acute hospitals. The results indicate that all HAl types were distributed throughout the different specialties. At individual specialty level, all the HAI categories contribute to the burden of HAl. For example, $71 \%$ of the $247 \mathrm{HAl}$ in surgical inpatients and $57 \%$ of the $105 \mathrm{HAl}$ in orthopaedic inpatients were in categories other than surgical site infection. Among 'care of the elderly' inpatients, $68 \%$ had infections other than urinary tract infection and pneumonia. Dentistry specialty results should be interpreted with caution as the numbers are very small $(N=2)$.

The prevalence of $\mathrm{HAl}$ in patients in acute hospitals was found to be $9.5 \%$ (95\% Cl: 8.8 10.2). Differences between populations sampled and in survey methodology may render comparisons between the results of HAl prevalence surveys inappropriate. ${ }^{6}$ These include differences in the populations studied (hospital type and practice, year of study, type and case mix of patients) and methodological issues, including $\mathrm{HAl}$ case definitions and their application in case ascertainment. It is coincidental, therefore, that this $9.5 \%$ prevalence estimate in acute hospitals is similar to that reported in UK surveys in 1980 and in 1993 1994. ${ }^{7,8}$ The population studied in this Scottish survey was, however, older than those studied in these two UK studies. An HAl prevalence survey of acute hospitals was undertaken in England, Wales, Northern Ireland and the Republic of Ireland (the HIS survey in 2006) over a four-month (February to May) period during the year the Scottish survey was undertaken, which used the same HAl definitions. ${ }^{913}$ In this survey of volunteer hospitals a prevalence of $7.6 \%$ (combined England, Wales, Northern Ireland and the Republic of Ireland) was reported in a survey of 75765 patients in 273 acute hospitals. However, even in this survey there are differences in patient case mix and aspects of the methodology which mean 
that a comparison of the unadjusted, overall $\mathrm{HAl}$ prevalence rate with that reported here should also be made with caution.

Some prevalence surveys concentrate on a subset of HAl types. ${ }^{14,15}$ These often include four infections: pneumonias, urinary tract infections, surgical site infections and bloodstream infections. This survey found an overall prevalence in these infection types of $5 \%$; nevertheless, these were not the most common and accounted for only about half of all HAls identified.

Various studies have reported variation in HAI prevalence by specialty. ${ }^{7,16} 20$ This survey found the highest prevalence of HAl in acute hospital inpatients in the following specialties: care of the elderly $(11.9 \%)$, surgery $(11.2 \%)$, medicine $(9.6 \%)$ and orthopaedics (9.2\%) (Table II). One implication of this observation is the importance of emphasising hospital-wide infection control policies and practice, such as standard precautions, which can reduce the prevalence of a wide range of HAls.

The most commonly recorded HAls among acute hospital patients in this study were, in order of proportions of all HAl found: urinary tract infections $(17.9 \%)$, surgical site infections $(15.9 \%)$, and gastrointestinal infections $(15.4 \%)$; respiratory tract infections $(11.2 \%)$, skin and soft tissue (11.0\%) were also prominent.

The spectrum of HAl occurring in acute hospital patients is wide. This is also the case at the level of individual specialties. Most if not all types of HAl occur in patients in every specialty. However, as would be expected, patients in some specialties have a higher prevalence of HAl than others. It may be that frequent patient movement between wards as part of bed management may result in more widespread occurrence of HAl.

Multiple infections were found in $1.1 \%$ of all inpatients (or $11.4 \%$ of acute hospital inpatients with HAI). These findings reinforce the differences between inpatient populations in each healthcare environment, and, for similar reasons, emphasise that prevalence of patients with multiple infections reported in previous surveys should only be compared with caution. Meers et al. found that $5.6 \%$ of $\mathrm{HAl}$ inpatients had more than one HAl, but surveys in Germany, Italy, Switzerland and Slovenia suggest that this statistic can range from $4.1 \%$ to $21.2 \%$. ${ }^{7,15,18,19,21}$ This broad range is probably indicative of differences in survey methodology and diagnostic rigour, as much as differences in the surveyed populations.

The prevalence of HAl in patients in non-acute hospitals was found to be $7.3 \%(95 \% \mathrm{Cl}: 6.0$ 8.6), i.e. lower than that in acute hospitals. Differences in the specialty distributions and case mix in the acute and non-acute hospital populations may account for this difference.

There are few surgical patients in the non-acute hospital population, whereas psychiatric patients, a group with a relatively low prevalence of $\mathrm{HAI}(5 \%)$, make up just over $50 \%$ of the population. In other reports where HAI prevalence has been found to be similar or higher than that in acute hospitals, it is probable that differences in the population sampled, e.g. age and case-mix, and in methodology, account for the differing result. ${ }^{22,23}$

$\mathrm{HAl}$ infection type contributing to the burden of HAl in non-acute hospitals was different from that in acute care (Tables I and II). Among non-acute hospital patients urinary tract infections were frequent, but equally frequent were skin and soft tissue infections. Taken together these affected about $4 \%$ of the inpatients, and almost two-thirds of psychiatry HAls were skin and soft tissue or urinary tract infections. Multiple HAl infections were found in $1.0 \%$ of non-acute inpatients (i.e. $4.5 \%$ of non-acute hospital inpatients with $\mathrm{HAl}$ had more than one infection).

In conclusion, this survey describes the prevalence of HAl in Scotland. It has established, for the first time, the burden and epidemiology of HAl in Scotland.

\section{Acknowledgements}

We thank the infection control and ward staff in all of the participating hospitals for their cooperation and support, and the Scottish National HAI Prevalence Survey team for the dedicated data collection.

\section{Conflict of interest statement}

None declared.

\section{Funding source}

The Scottish Executive Health Department HAI Task Force funded this project.

\section{References}

1. Harbarth S, Sax H, Gastmeier P. The preventable proportion of nosocomial infections: an overview of published reports. J Hosp Infect 2003;54:258-266.

2. Ayliffe GA. Nosocomial infection - the irreducible minimum. Infect Control 1986;7(Suppl.):S92-S95.

3. Plowman R, Graves N, Griffin M, et al. The socio-economic burden of hospital acquired infection, Part 1. London: PHLS; 1999.

4. Centers for Disease Control and Prevention. National nosocomial infection study site definition manual. Atlanta, GA: Centers for Disease Control and Prevention; 1999. 
5. Information Services Division. Available beds by specialty \& NHS board of treatment. Scotland: ISD; 2006.

6. Gastmeier P, Kampf G, Wischnewski N, Schumacher $M$, Daschner $F$, Ruden $H$. Importance of the surveillance method: national prevalence studies on nosocomial infections and the limits of comparison. Infect Control Hosp Epidemiol 1998;19:661-667.

7. Meers PD, Aycliffe GA, Emmerson AM, et al. Report on the national survey of infection in hospitals. J Hosp Infect 1980;2(Suppl.):S1-S11.

8. Emmerson AM, Enstone JE, Kelsey MC. The second national prevalence survey of infection in hospitals: methodology. J Hosp Infect 1995; 30:7-29.

9. Hospital Infection Society, Infection Control Nurse Association. Summary of preliminary results of third prevalence survey of healthcare-associated infections in acute hospitals 2006 - Wales. National Public Health Service for Wales, Welsh Assembly Government; 2007.

10. Hospital Infection Society, Infection Control Nurse Association. Summary of preliminary results of third prevalence survey of healthcare-associated infections in acute hospitals 2006 - England. Hospital Infection Society/Infection Control Nurses Association; 2007.

11. Hospital Infection Society, Infection Control Nurse Association. Summary of preliminary results of third prevalence survey of healthcare-associated infections in acute hospitals 2006 - Northern Ireland. Department of Health, Social Services and Public Safety, Northern Ireland HealthcareAssociated Infection Surveillance Centre; 2007.

12. Hospital Infection Society, Infection Control Nurses Association. Summary of preliminary results of third prevalence survey of healthcare-associated infections in acute hospitals 2006 - Republic of Ireland. Health Service Executive, Health Protection Surveillance Centre; 2007.
13. Hospital Infection Society. National prevalence survey results. Amsterdam: Hospital Infection Society; 2006.

14. Eriksen HM, Iversen BG, Aavitsland P. Prevalence of nosocomial infections in hospitals in Norway, 2002 and 2003. J Hosp Infect 2005;60:40-45.

15. Klavs I, Bufon Luznik T, Skerl M, et al. Prevalance of and risk factors for hospital-acquired infections in Slovenia - results of the first national survey, 2001. J Hosp Infect 2003;54: 149-157.

16. Emmerson AM, Enstone JE, Griffin M, Kelsey MC, Smyth ET. The second national prevalence survey of infection in hospitals - overview of the results. J Hosp Infect 1996; 32:175-190.

17. Nicholls TM, Morris AJ. Nosocomial infection in Auckland healthcare hospitals. N Z Med J 1997;110:314-316.

18. Gastmeier P, Kampf G, Wischnewski N, et al. Prevalence of nosocomial infections in representative German hospitals. J Hosp Infect 1998;38:37-49.

19. Zotti CM, Messori Ioli G, Charrier L, et al. Hospital-acquired infections in Italy: a region wide prevalence study. $J$ Hosp Infect 2004;56:142-149.

20. Vaque J, Rossello J, Arribas JL. Prevalence of nosocomial infections in Spain: EPINE study 1990-1997. EPINE Working Group. J Hosp Infect 1999;43(Suppl.):S105-S111.

21. Pittet D, Harbarth $S$, Ruef $C$, et al. Prevalence and risk factors for nosocomial infections in four university hospitals in Switzerland. Infect Control Hosp Epidemiol 1999;20:37-42.

22. Standfast SJ, Michelsen PB, Baltch AL, et al. A prevalence survey of infections in a combined acute and long-term care hospital. Infect Control 1984;5:177-184.

23. Steinmiller AM, Robb SS, Muder RR. Prevalence of nosocomial infection in long-term-care veterans administration medical centers. Am J Infect Control 1991;19:143-146. 